\title{
Statistical estimations of atmospheric duct over the South China Sea and the Tropical Eastern Indian Ocean
}

\author{
ZHAO XiaoFeng ${ }^{1,2^{*}}$, WANG DongXiao ${ }^{2 *}$, HUANG SiXun ${ }^{1}$, HUANG $\mathrm{Ke}^{2} \& \mathrm{CHEN} \mathrm{Ju}^{2}$ \\ ${ }^{1}$ Institute of Meteorology and Oceanography, PLA University of Science and Technology, Nanjing 211101, China; \\ ${ }^{2}$ State Key Laboratory of Tropical Oceanography, South China Sea Institute of Oceanology, Chinese Academy of Sciences, Guangzhou 510301, China
}

Received January 28, 2013; accepted April 24, 2013; published online June 18, 2013

\begin{abstract}
In 2010-2012 spring, atmospheric duct observation experiments were performed throughout three open cruises over the South China Sea and the Tropical Eastern Indian Ocean. The data used for ducting analysis were measured by high resolution balloon-borne GPS radiosondes. Through data quality control and diagnostic analysis, the probability of ducting occurrence and characteristic quantities of the three typical ducts were given. The total percentage occurrence of evaporation duct, surface-based duct and elevated duct were $75.3 \%, 5 \%$ and $43.7 \%$, respectively. The mean evaporation duct height was $15.3 \mathrm{~m}$. The mean values of duct height, thickness and magnitude were $84.1 \mathrm{~m}, 14.9 \mathrm{~m}$ and $10 \mathrm{M}$-units for surfaced-based duct, and $1003.6 \mathrm{~m}, 62.2 \mathrm{~m}$ and 7.9 M-units for elevated duct. These preliminary statistical results can serve as a basis for future comprehensive and comparative studies of atmospheric duct for the research region.
\end{abstract}

open cruise, GPS radiosonde, atmospheric duct

Citation: Zhao X F, Wang D X, Huang S X, et al. Statistical estimations of atmospheric duct over the South China Sea and the Tropical Eastern Indian Ocean. Chin Sci Bull, 2013, 58: 2794-2797, doi: 10.1007/s11434-013-5942-8

Atmospheric duct occurs frequently in the lower marine troposphere. The duct can result in nonstandard electromagnetic propagation of radar systems and wireless communications. These include extending the maximum detection range, creating radar holes, and enhancing radar clutter returns, etc. [1,2]. Therefore, an exact knowledge of duct information will help to improve the operational performance of communication systems. The Strait of Malacca and Sunda link the Indian Ocean and the Pacific, and both of them are very important shipping channels in the world. However, due to the lack of high resolution observations, there are very few studies of atmospheric duct for this region and its nearby waters.

An effective method for duct detection is to use radiosonde to measure height dependence of temperature, pressure and humidity [3-5]. Although there are roughly 850 radiosonde stations in the global range, their geographic

*Corresponding authors (email: zxf_best@126.com; dxwang@ scsio.ac.cn) distribution is inhomogeneous and the density over the oceans is very low [6]. Thus, more cruise observations and other remote sensing products are expected to make up these vacancies.

The data used in this paper were collected during three spring cruises by 'ShiYan 1' Research Vessel, which took place from Apr 12 to May 27, Mar 31 to May 15, Feb 25 to Apr 20 in 2010, 2011 and 2012, respectively. The key source of the data was measured by high resolution balloonborne GPS radiosondes that were released four times a day $(0000,0600,1200$, and 1800 UT) to collect vertical profiles of atmospheric pressure, temperature, relative humidity, wind speed, etc. Compared with classical radiosone, GPS radiosonde has higher vertical resolution that makes the diagnosis of small duct structures possible. The pictures of 'ShiYan 1' Research Vessel and a balloon-borne GPS radiosonde release process are shown in Figure 1.

To identify duct conditions, one can simply look for regions where the vertical gradient of the modified refractivity 

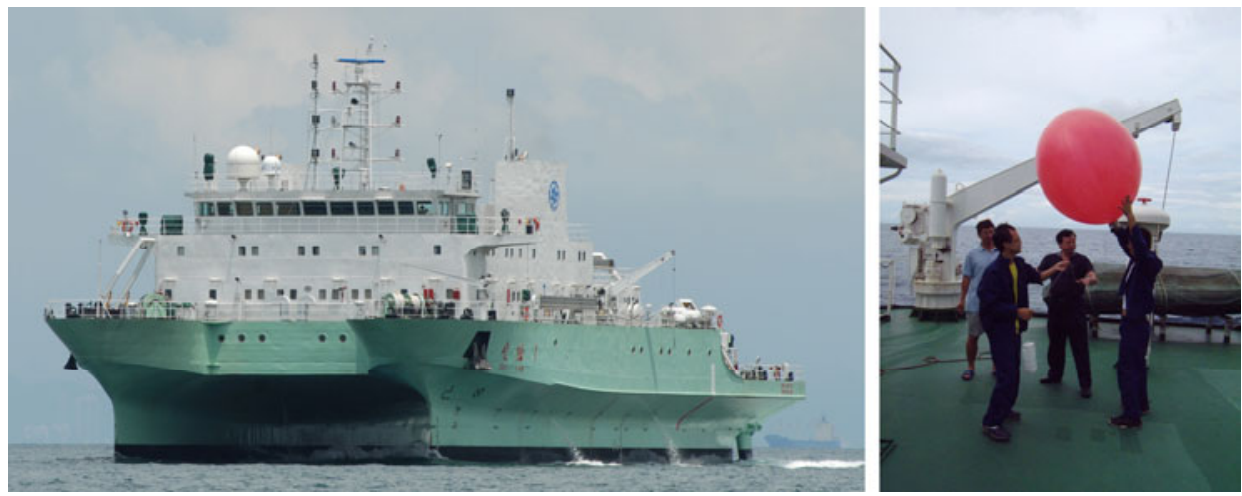

Figure 1 (Color online) 'ShiYan 1' Research Vessel (left) and a balloon-borne GPS radiosonde release process (right).

is negative [7]. The relationship between the observations and the modified refractivity $M$ can be described as [8]:

$$
M=\frac{77.6}{T}\left(p+\frac{4810 e}{T}\right)+0.157 z,
$$

where $T$ is the atmospheric temperature, $p$ is the total atmospheric pressure, $e$ is the water vapor pressure and $z$ is the altitude. From eq. (1), we could see that a duct occurrence is usually accompanied by temperature inversion and/ or rapid decrease of moisture.

Previous radiosonde refractivity studies pointed out that the most ducting events were found below $2 \mathrm{~km}[9,10]$. Thus, the maximum computation height in this paper was limited to $2 \mathrm{~km}$. Before taking statistics, several quality control methods were used to eliminate unreasonable meas- urements. Through examining the raw data and the corresponding visible figures, first evident inaccurate datasets were eliminated, then, using the gradient information, singular points were found by the internal consistency and continuity check. Last, the data were spline interpolated to a vertical grid with $1 \mathrm{~m}$ resolution below 100, 2 m resolution between 100 and $200 \mathrm{~m}$, and $5 \mathrm{~m}$ resolution above $200 \mathrm{~m}$. The cruise tracks and valid GPS radiosonde data collection locations are shown in the top plots of Figure 2.

Table 1 gives the probability of occurrence of the three typical ducts for the research region, where EvaD means evaporation duct, SurD means surface-based duct and EleD means elevated duct. The percentage occurrences were obtained by dividing the total number of duct events by the total number of valid radiosonde releases. The deck height
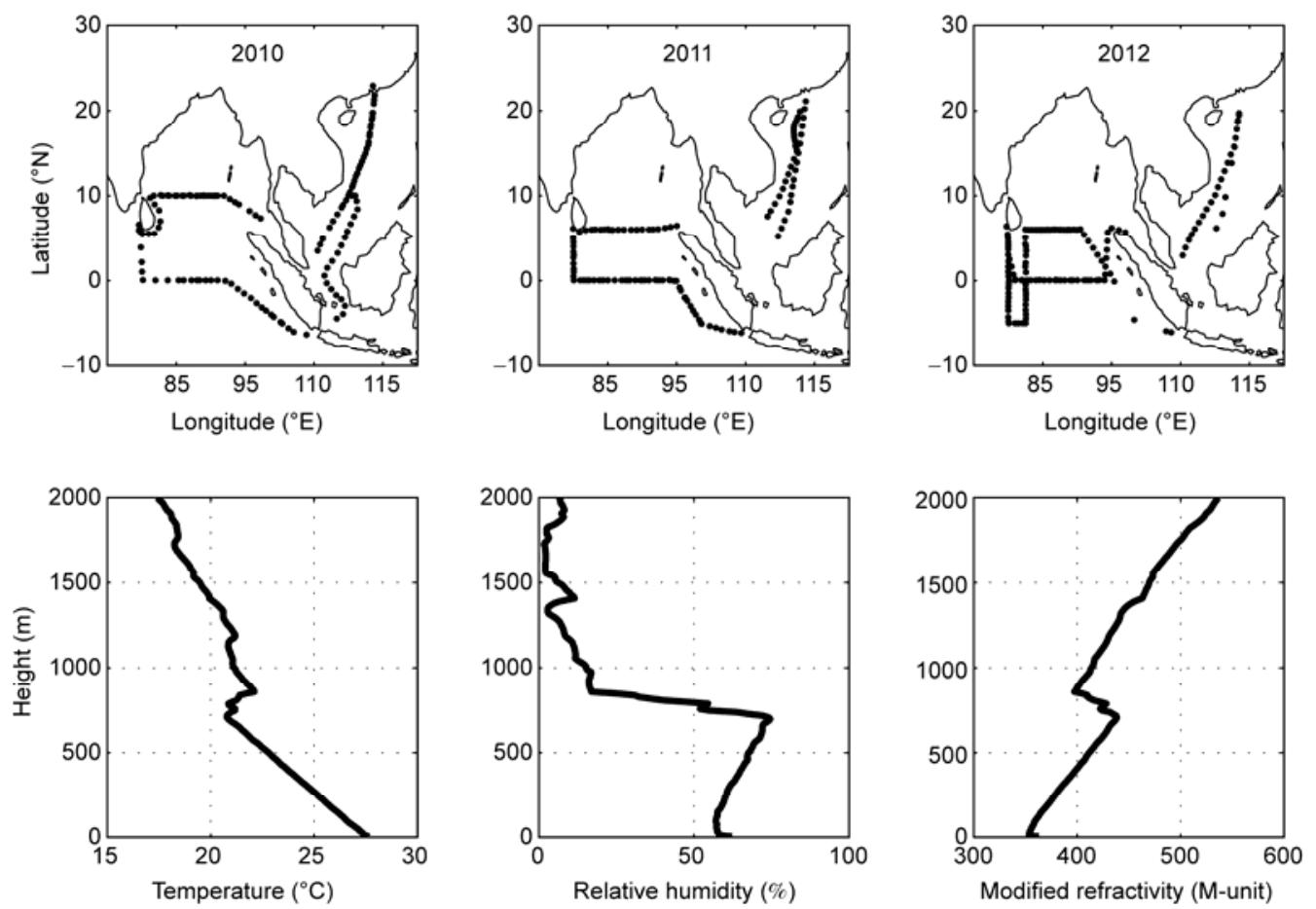

Figure 2 Cruise tracks and valid GPS radiosonde data collection locations for 2010, 2011 and 2012, respectively (top). An observation case of temperature, relative humidity and modified refractivity profiles at $1200 \mathrm{UT}$ on March 11, 2012 (bottom). 
Table 1 Probability of occurrence of the three typical ducts for the research region

\begin{tabular}{ccccc}
\hline Time & 2010 & 2011 & 2012 & $2010-2012$ \\
\hline EvaD & $88 / 122(72.1 \%)$ & $93 / 121(76.9 \%)$ & $105 / 137(76.6 \%)$ & $286 / 380(75.3 \%)$ \\
SurD & $5 / 122(4.1 \%)$ & $7 / 121(5.8 \%)$ & $7 / 137(5.1 \%)$ & $19 / 380(5.0 \%)$ \\
EleD & $52 / 122(42.6 \%)$ & $47 / 121(38.8 \%)$ & $67 / 137(48.9)$ & $166 / 380(43.7 \%)$ \\
\hline
\end{tabular}

of 'ShiYan 1' Vessel is nearly $4 \mathrm{~m}$ above the sea surface, thus only the duct heights greater than $4 \mathrm{~m}$ were considered.

From Table 1, it is observed that evaporation duct is frequently encountered in the South China Sea and the Tropical Eastern Indian Ocean, and the total probability of occurrence is more than $75 \%$. Compared with the evaporation duct, surface-based duct occurrence is very small and its total probability is just $5 \%$. Elevated duct occurrence is moderate of the three with probability of $43.7 \%$. This occurrence distribution could be attributed to (1) in the tropical oceans, the seawater evaporation is very strong and the moisture decreases rapidly in very few meters, which provide good conditions for the formation of evaporation duct; (2) surface-based duct is always due to the presence of strong radiation cooling over land and/or prevalence of localized land-sea breeze [5]. However, these conditions are difficult to meet over the research region; and (3) temperature inversions are generally associated with a decrease in moisture and the result is often a trapping layer [11], which might be the reason for the formation of elevated duct. An observation case at 1200 UT on March 11, 2012 is shown in the bottom plots of Figure 2. In the first few meters, there exists an evaporation duct (18 $\mathrm{m}$ height). While in the upper layer, there exists an elevated duct (860 m height).

Although the sailing time is restricted to spring and the area is restricted to the South China Sea and the Tropical Eastern Indian Ocean, a certain temporal and spatial difference still exists, which results in small interannual differences (Table 1). However, this does not affect a rough statistics for this region. To describe an atmospheric duct in detail, some characteristic quantities are defined, such as duct height for evaporation duct, duct height, thickness and magnitude/M-deficit for surface-based and elevated ducts [12]. Figure 3 presents the histogram distributions for the characteristic quantities of the three typical ducts using all the observations from 2010 to 2012. The mean values for each characteristic quantity are also given.

For evaporation duct, the duct height is less than $40 \mathrm{~m}$. Most of the heights are concentrated between 10 and $20 \mathrm{~m}$, and the mean value is $15.3 \mathrm{~m}$. This value is higher than the global mean height $13 \mathrm{~m} \mathrm{[13]} \mathrm{and} \mathrm{the} \mathrm{height} \mathrm{off} \mathrm{the} \mathrm{south-}$ eastern coastal area of China is $10 \mathrm{~m}$ [14]. Although the evaporation ducts are near the sea surface, they have a significant impact on ship-borne communications above $2 \mathrm{GHz}$ [15]. For surface-based duct, the available data for this type of duct are few, and the statistical properties are not obvious.
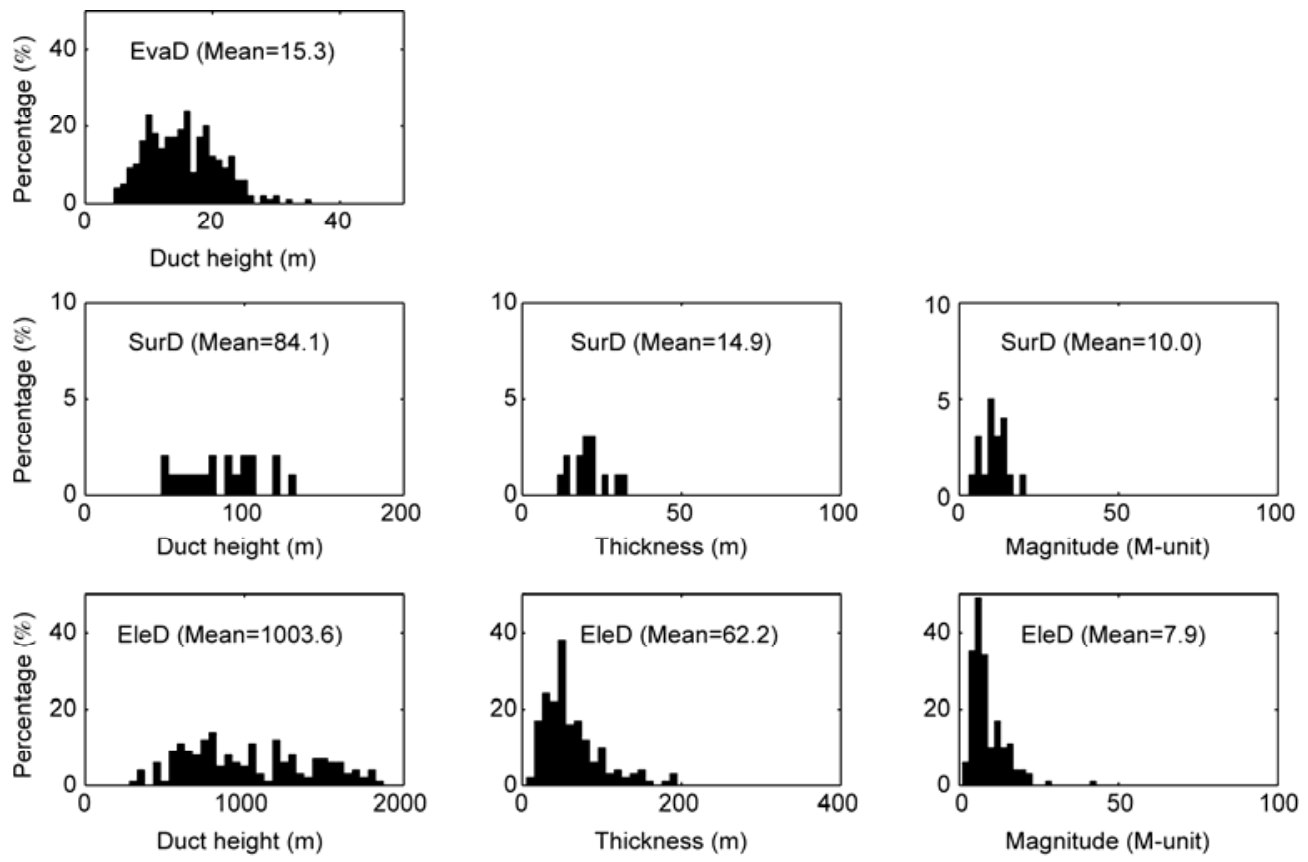

Figure 3 Histograms showing the percentage occurrence of the duct characteristic quantities of all the observations from 2010 to 2012 . The top plot is for evaporation duct, the middle plots are for surface-based duct and the bottom plots are for elevated duct. 
However, the trapping ability of surface-based duct is much stronger than evaporation duct. For elevated duct, the duct height ranges from 250 to $2000 \mathrm{~m}$ and the mean value is $1003.6 \mathrm{~m}$, which is similar to the height of marine atmospheric boundary layer over this region [11]. The extreme values for the duct thickness and magnitude are respectively located at 50-60 and 6-8 m. Through mass observations (evaporation and elevated duct), we can also find that the characteristic quantities approximate normal distributions. The interannual variability of the mean value of the duct characteristic quantities is shown in Table 2.

The observations in this study are limited to the spring. However, over the tropical oceans, the climate conditions have not distinct seasonal changes. Thus, the preliminary results might be applicable to the whole year atmospheric

Table 2 Interannual variability of the mean value of the duct characteristic quantities

\begin{tabular}{lrrr}
\hline \multicolumn{1}{c}{ Time } & 2010 & 2011 & 2012 \\
\hline EvaD height (m) & 15.7 & 15.2 & 15.1 \\
SurD height (m) & 96.4 & 72.1 & 87.1 \\
SurD thickness (m) & 18.0 & 12.4 & 15.1 \\
SurD magnitude (M-unit) & 10.1 & 10.9 & 9.0 \\
EleD height (m) & 916.9 & 1026.4 & 1043.5 \\
EleD thickness (m) & 71.5 & 58.3 & 58.7 \\
EleD magnitude (M-unit) & 7.0 & 7.3 & 8.7 \\
\hline
\end{tabular}

duct evaluations and they can also serve as a basis for future comprehensive and comparative studies of atmospheric duct for this region.

The authors thank Dr. Li Jian of the Key Laboratory of Tropical Marine Environmental Dynamics, South China Sea Institute of Oceanology for helpful discussions about data processing. This work was supported by the National Basic Research Program of China (2011CB403504) and the National Natural Science Foundation of China (41175025).

1 Yan H J, Fu Y, Hong Z J. Introduction to Modern Atmospheric Refraction (in Chinese). Shanghai: Science and Educational Press, 2006

2 Zhao X F, Huang S X. Prog Electromagn Res B, 2011, 33: 153-174

3 Helvey R A. IEE Proc, 1983, 130: 643-648

4 Babin S M, Rowland J R. Geophys Res Lett, 1992, 19: 917-920

5 Mentes S S, Kaymaz Z. J Appl Meteorol Clim, 2007, 46: 318-337

6 Kuo Y H, Schreiner W S, Wang J, et al. Geophys Res Lett, 2005, 32: L05817

7 Zhao X F, Huang S X. J Atmos Sci, 2012, 69: 2808-2818

8 Ali S, Malik S A, Alimgeer K S, et al. J Atmos Sol-Terr Phy, 2012, 77: 96-103

9 Kursinski E R, Hajj G A, Schofield J T, et al. J Geophys Res, 1997, 102: 23429-23465

10 Engeln A V, Teixeira J. J Geophys Res, 2004, 109: D18104

11 Wang D X, Zhou W, Yu L X, et al. Atmos Oceanic Sci Lett, 2010, 3: 263-270

12 Gerstoft P, Rogers L T, Krolik J, et al. Radio Sci, 2003, 38: 8053

13 Yardim C, Gerstoft P, Hodgkiss W S. Radio Sci, 2003, 44: RS1008

14 Liu C G, Huang J Y, Jiang C Y. Chin J Radio Sci, 2002, 17: 509513

15 Barrios A E. Naval Ocean Systems Center Tech Rep, 1430, 1991

Open Access This article is distributed under the terms of the Creative Commons Attribution License which permits any use, distribution, and reproduction in any medium, provided the original author(s) and source are credited. 